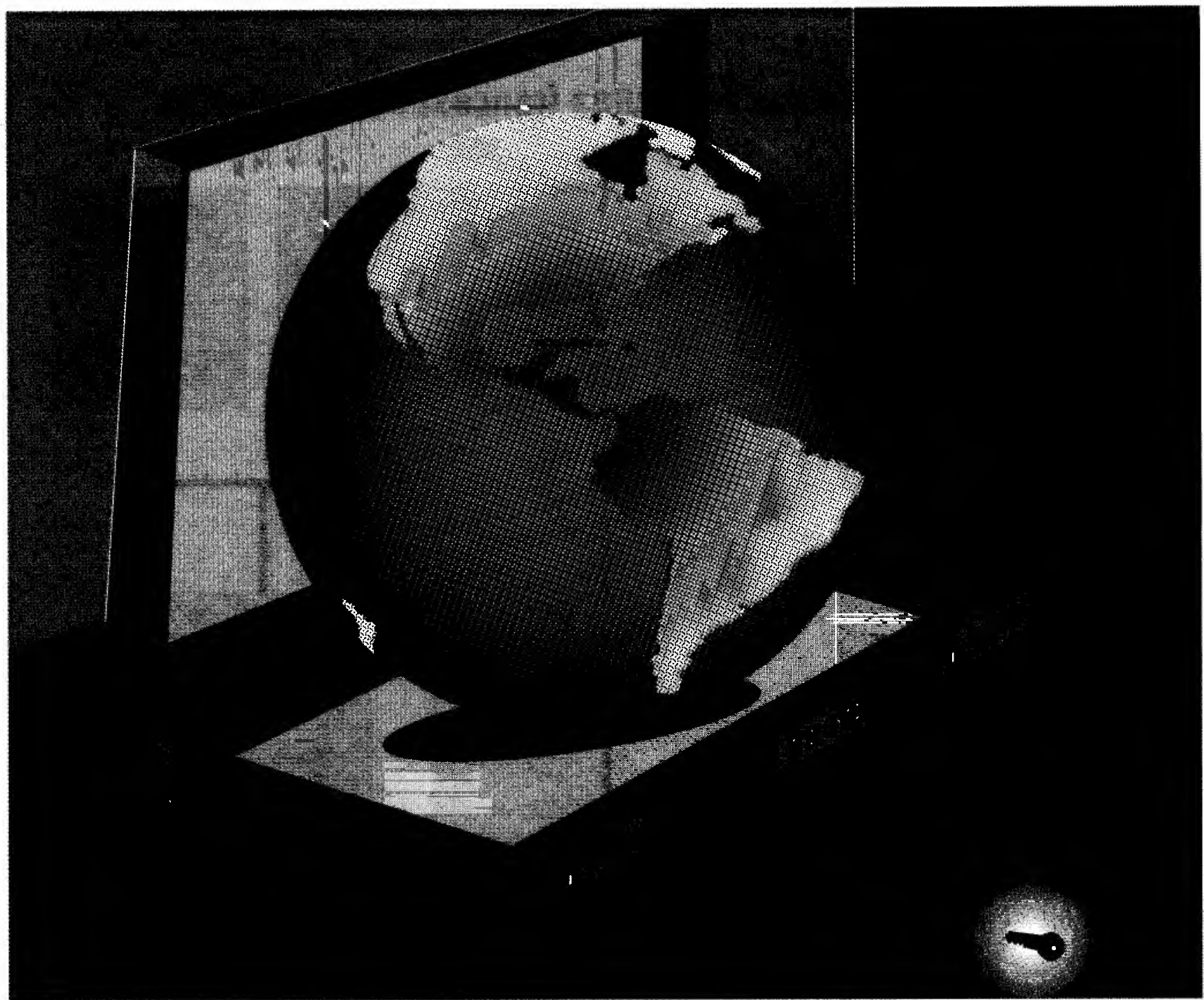

\title{
MARKETING GLOBAL: CONCEITO OU MITO?
}

Carlos Alcides Salles

Professor do Departamento de Mercadologia da EAESP/FGV.

* RESUMO: O conceito de Marketing Global, desenvolvido por Theodore Levitt, é considerado como um dos mais polêmicos dentro da literatura de Marketing. Este ano, o conceito completa dez anos e continua a gerar polêmica entre os estudiosos e praticantes do Marketing, sendo que o único ponto comum é que o conceito em sua forma pura como proposta por Levitt se mostrou impraticável. Portanto, este artigo pretende analisar a validade ou não do Conceito de Marketing Global e para isso se utiliza tanto da bibliografia elaborada pelos críticos do conceito, bem como de autores como Jain, Porter e Takeuschi que procuraram contribuir para torná-lo operacional.
* PALAVRAS-CHAVE: Marketing global, segmentação de mercado, composto mercadológico, padronização.

* ABSTRACT: The Levitt's Concept of Global Marketing is still one of the most controversal. There in the marketing literature. Even now after ten years of it's creation it has been causing a polemical debate which the only point of consensus is that the pure globalization form has not been showned practical. This article discuss the validity of Global Marketing Concept. In order to do so the author uses the critical literature on the subject as well as Jain's, Porter and Takeuschi's works which tired and practical approach.

* KEY WORDS: Global marketing, market-segmentation, marketing mix, standardization.

São Paulo, 33(4):32-39

Jul./Ago. 1993 
A preocupação com a possibilidade de padronização de alguns elementos da estratégia de marketing surgiu no ínicio da década de 60 e teve como preocupação básica a utilização da mesma propaganda em diversos países. $O$ argumento utilizado por Elinder ${ }^{1}$, considerado autor pioneiro neste enfoque, foi a emergência de similaridade entre os consumidores europeus que permitiria a utilização de uma propaganda uniforme. De certa forma, podemos considerar que, até os anos 80 , a maior parte dos estudos realizados sobre a tendência de globalização de mercados se deu no campo da propaganda.

Apesar da publicação do artigo de Buzzell $^{2}$ a respeito da possibilidade de empresas multinacionais padronizarem seu marketing, a preocupação do autor não estava centrada somente na padronização da estratégia mercadológica, mas também na coordenação das atividades de marketing.

Foi somente em 1983, com a publicação do artigo "A Globalização de Mercados $^{\prime \prime}$, que Theodore Levitt ${ }^{3}$ estabeleceu as bases do que se tornaria conhecido como Marketing Global, ou seja, adotar uma estratégia mercadológica padronizada para todos os mercados. Neste ponto é importante fazermos a distinção entre Marketing Global, que age como se o mundo fosse um grande mercado de preferências homogêneas e Estratégia Global, que significa a centralização do planejamento e da coordenação das atividades de marketing, a fim de definir a forma de competição que as empresas irão adotar a nível global. Neste sentido, o conceito proposto por Levitt poderia ser considerado como apenas uma das possibilidades dentro de uma ampla variedade de estratégias possiveis.

Este artigo tem como preocupação fundamental demonstrar que o conceito de Marketing Global desenvolvido por Levitt constitui mais um dos mitos de marketing e que as tentativas de vários autores para validá-lo foram de tal maneira restritivas que o transformaram em algo vago, impreciso e de utilidade limitada.

\section{MARKETING GLOBAL NAS PALAVRAS DE SEU CRIADOR E ALGUMAS RESTRIÇÕES}

Após o grande impacto gerado na década de 60 pela publicação de seu artigo
"Marketing Myopia $^{4}{ }^{4}$, hoje considerado leitura obrigatória por todos aqueles que se interessam por marketing, Theodore Levitt agitou novamente os meios acadêmicos e empresariais com o conceito de globalização dos mercados. $^{5}$

Para o autor, as seguintes tendências apontam para esta direção:

\section{1. as necessidades dos} consumidores têm se tornado homogêneas devido à tecnologia, que permitiu a "proletarização" das comunicações, viagens e transportes;

2. os consumidores estão dispostos a sacrificar suas preferências (desenho, versões etc.) em favor de preços baixos e alta qualidade;

3. ganhos de economia de escala em produção e marketing no atendimento dos mercados globais.

Portanto, estas tendências servem como pressupostos para o autor afirmar que "A teoria dominante é que se você forçar os custos $e$ os preços para baixo e empurrar para cima a qualidade e a confiabilidade em tudo, em todos os lugares do mundo os clientes preferirão suas ofertas genéricas mundialmente padronizadas, e em proporção crescente. E não importa o que a pesquisa convencional de mercado e até as observações comuns possam sugerir quanto à existência de gostos, preferências, necessidades e instituições diferentes, nacionais e internacionais" 6 e "A corporação multinacional e a global não são a mesma coisa. A empresa multinacional opera em numerosos países, nos quais, em cada caso, ajusta-se com especiais cuidados $e$, portanto, com custos relativamente altos para as presumidas condições especiais de determinado país. Em contraste, a corporação global opera com constância resoluta e, por isso, a custos relativamente baixos, como se o mundo (ou a maior parte dele) fosse uma única entidade: ela faz $e$ vende as mesmas
1. ELINDER, Erik. How international can advertising be? International Advertiser, December/1961, p. 12-16.

2. BUZZELL, Robert D.; GALE, Bradley. Can you standardize multinational marketing? Harvard Business Review, Nov. Dec./1968, p. 102-13.

3. LEVITT, Theodore. A globalização em marketing. Marketing Imagination. New York: Free Press, 1983 - Utilizaremos para citaçōes e referências a edição brasileira: A Imaginação em Marketing. São Paulo: Atlas, 1985.

4. LEVITT, Theodore. Marketing Myopia. Harvard Business Review, Jul./Aug. 1960. Faremos uso da edição em português Miopia em Marketing. São PauIo: Biblioteca Harvard de Administração, v. 1, n. 1, 1975

5. LEVITT, Theodore. Marketing Imagination. Op. cit. (Conferir especialmente o capítulo II.)

6. Idem, ibidem, p. 39. 


\begin{tabular}{c}
\hline A percepção de \\
melhor qualidade por \\
parte do consumidor \\
permite a utilização de \\
uma estratégia de preços \\
diferenciados, evitando \\
o frágil posicionamento \\
baseado em preço.
\end{tabular}

coisas, sempre da mesma maneira, em todos os lugares." 7

Praticamente estes dois trechos definem o pensamento de Levitt a respeito do que vem a ser o Marketing Global. Os pressupostos e a conclusão de Levitt não são baseados nas "pesquisas convencionais de mercado" (seja lá o que isto signifique para ele), nem em estudos empíricos sobre as possíveis empresas que tenham adotado este conceito, e, por último, nem em "observações comuns", o que nos leva a crer que o único elemento de análise são as observações não comuns do próprio Levitt.

Algumas empresas como Coca-Cola, McDonald's, Canon, Esso e outras foram alvo dessas observações incomuns, e tipificadas como globais por "fazerem e venderem as mesmas coisas, sempre da mesma maneira, em todos os lugares. “ Entretanto, outros autores ${ }^{8}$ mostram que a Coca-Cola não preenche as condições de empresa global proposta por Levitt, tendo em vista que diferentes fórmulas são usadas em diferentes regiões e diferentes países, o tamanho das embalagens é diferenciado de acordo com os hábitos de cada país e as campanhas publicitárias são adaptadas às diferenças culturais. A cadeia McDonald's oferece cerveja apenas na Alemanha (tendo em vista a resistência dos adultos em consumirem refrigerantes durante as refeições) e o sanduíche cheese-salada é oferecido apenas nas lojas brasileiras. A Canon, com as câmaras automáticas de $35 \mathrm{~mm}$, utilizava posicionamento diferente de acordo com o estágio em que o produto se encontrava no ciclo de vida em cada mercado, além de adaptar suas estratégias de preço, distribuição e promoção. A Esso, embora utilize a mesma mensagem de comunicação, altera a composição do combustível em função de cada país. Podemos concluir que as próprias empresas caracterizadas por
Levitt como globais, de alguma forma adaptam seu mix de marketing em função do mercado em que participam, o que, em última instância, aponta para a não homogeneização dos mercados e das necessidades dos consumidores. ${ }^{9}$

Entretanto, há evidências da existência de alguns segmentos globais para produtos de luxo que permitem manter inalterado o mix de marketing, como, por exemplo, automóveis (Mercedes, Ferrari, BMW ), relógios (Rolex, Omega, Baume \& Mercier), roupas (Armani, Dior, Cardin), canetas (Mont Blanc, Omas, Dupont, Cartier). Mas, estes casos podem ser considerados como exceções e não regra, principalmente se lembrarmos que em toda história humana sempre houve uma demanda universal para produtos de luxo (sejam eles jóias, especiarias etc.).

Em segundo lugar, não há evidências de que o consumidor esteja disposto a sacrificar suas preferências por produtos de qualidade aceitável e baixo preço. Em estudos realizados, por Buzzel e Gale ${ }^{10}$, qualidade é apontada como um elemento de importância fundamental na estratégia das empresas bem-sucedidas na conquista de participação de mercado, além de possibilitar a prática de preços mais elevados. Em outras palavras, a percepção de melhor qualidade por parte do consumidor permite a utilização de uma estratégia de preços diferenciados, evitando o frágil posicionamento baseado em preço (facilmente atacado por empresas com custos menores ou por evoluções tecnológicas). Este fato parece comprovar a hipótese de que o consumidor está disposto a despender mais dinheiro por um produto de qualidade superior.

Em terceiro lugar, a economia de escala pode ser alcançada não apenas pelo aumento do volume produzido mas também por processos flexíveis de produção, automação, novos processos produtivos, eficiência no processo de distribuição etc. Além do que a economia de escala é resultado do aumento de participação de mercado pelo atendimento eficaz das necessidades dos consumidores. Portanto, ela é obtida em função da adoção de uma consistente estratégia mercadológica. $\mathrm{Na}$ situação inversa, ou seja, tendo-se como ponto de partida a economia de escala, estaríamos adotando uma forte orienta- 
ção para o produto em detrimento da orientação para o mercado.

É curioso notar que a economia de escala, tão duramente criticada por Levitt, tornou-se, após 20 anos, um de seus três pressupostos para justificar o Marketing Global. Pensamos que Levitt caiu na mesma armadilha que denunciou em Miopia em Marketing: "As indústrias de produção em massa estão sujeitas a uma força que as impele a produzir tudo que podem. A possibilidade de reduzir dramaticamente os custos unitários à medida que aumenta a produção é algo que a maior parte das empresas não resiste. As perspectivas de maior lucro se afiguram espetaculares. Todos os esforços se concentram na produção. O resultado é que a parte de marketing fica esquecida. " 11

Todas estas restriçōes levam Douglas e Wind ${ }^{12}$ a afirmar que a adoção de uma estratégia universal padronizada parece ser exageradamente simplista e ingênua, e que a globalização é apenas uma entre as inúmeras possibilidades disponíveis de atuação.

Portanto, o processo de globalização não pode ser tratado como dicotômico, mas deve ser visto como gradativo. Este ponto de vista é compartilhado por diversos autores como Porter e Takeuchi, Jain, Keegan, Wind ${ }^{13}$ entre outros, que acreditam que os modelos puros, ou seja, uma estratégia totalmente padronizada ou totalmente desenhada para cada país em que a empresa atua é encontrada raramente. Logo, o trabalho a ser desenvolvido consiste em determinar quais são as variáveis mercadológicas passíveis de serem padronizadas e em quais situações isto se torna possível.

\section{UM CONCEITO EM BUSCA DE UMA APLICACÃO: AS TENTATIVAS DE PORTER, TAKEUSCHI E JAIN}

Para Porter e Takeuschi o Marketing Global deve se preocupar em realizar as tarefas de padronização e diferenciação simultaneamente: "A literatura de marketing internacional tem criado uma dicotomia entre padronizaçâo para todos os países e a adaptaçāo do marketing para cada país, nós mostramos que a tarefa essencial é fazer ambas simultaneamente". ${ }^{14}$

É a partir desta nova concepção de globalização que os autores tentam iden- tificar os fatores que contribuem ou limitam a adoção de uma estratégia padronizada de marketing e determinar quais os elementos do composto de marketing que são passíveis de padronização.

Porter e Takeuschi ${ }^{15}$ apontam como resultados de uma pesquisa realizada em seus estudos os seguintes itens do mix de marketing, em função da facilidade ou da dificuldade de padronização:

Os autores mostram, por exemplo, que

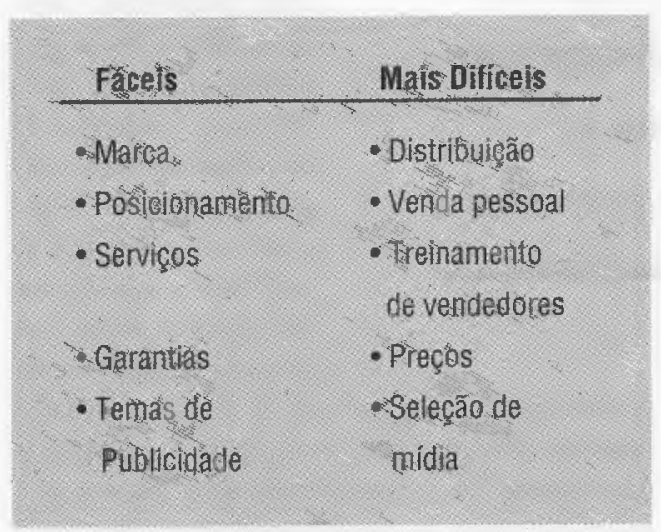

as diferenças encontradas na relação de atacadistas utilizadas para o produto chegar ao varejo é de 1,6:1 nos U.S.A., enquanto no Japão é de 4:1. A seleção de mídia também é afetada de acordo com a legislaçāo vigente em cada país. Keegan ${ }^{16}$ aponta que os anúncios de TV não existem nos países escandinavos; na França são permitidos apenas 18 minutos diários e na Itália, 80. Os preços dos produtos variam em função do desenvolvimento econômico de cada país. Desta forma, a adoção de um preço global pode conduzir a um preço superdimensionado em determinado país, enquanto em outro pode estar subdimensionado.

Mesmo o posicionamento, que, de acordo com Porter e Takeuschi, é de fácil padronização, pode se tornar um tema controvertido, pois pode ser dependente do estágio do ciclo de vida do produto em determinado mercado. Isto significa que estágios diferentes podem exigir estratégias diversas e até mesmo as diferenças apresentadas nas taxas de penetração do produto no mercado podem requerer posicionamentos alternativos de acordo com as características do mercado.

Lembramos que as garantias oferecidas variam em função das restrições legais e até mesmo em função da familiari-
11. LEVITT, Theodore. Miopia em marketing. Op. cit. p. 9.

12. DOUGLAS, Susan P.; WIND, Yoram. Op. cit.

13. PORTER, M.; TAKEUSCHI, $H$. Three Roles of International Marketing in Global Strategy. In: PORTER, M. Competition in Global Industries. Massachussets: Harvard Business School Press, 1986; JÄIN, S.C. Standardization of International Marketing Strategy: Some Research Hypotheses. Journal of Marketing Research, Jan. 1989, 0. 70 79; KEEGAN, W.J. Global Marketin Strategy. New Jersey: Prentice-Hall; $4^{a}$ ed., WIND, YOram. Op. cit.

14. PORTER, M.; TAKEUSCHI, H. Op. cit. p. 112.

15. Idem, ibidem, p. 127.

16. KEEGAN, W. J. Op. cit. $\rho$. 497. 


\section{Estágios diferentes podem}

exigir estratégias diversas $\mathrm{e}$

até mesmo as diferenças

apresentadas nas taxas de

penetração do produto no

mercado podem requerer

posicionamento alternativos

de acordo com as

características do mercado. dade dos consumidores com o produto. Por exemplo, em mercados em que o produto é amplamente conhecido e adotado, as garantias exigidas podem superar aquelas determinadas por lei. Em outras palavras, nestes mercados a garantia pode se tornar um elemento de diferenciação de produto. Em relação aos serviços, podemos observar que eles podem variar de acordo com a natureza do produto e do mercado a que ele atende. Por exemplo, um microcomputador comercializado numa região em que os consumidores não possuem familiaridade com o produto pode exigir uma ampla variedade de serviços para disseminar sua adoção. $\mathrm{O}$ mesmo produto em um mercado habituado com seu uso pode possibilitar a utilização de uma estratégia de redução de preços através da diminuição dos serviços, no caso do microcomputador eliminandose, por exemplo, o treinamento. Portanto, acreditamos que mesmos os elementos que os autores classificam como mais fáceis de serem padronizados podem, na verdade, depender de uma rigorosa análise para se determinar em que fase do ciclo de vida o produto se encontra em cada mercado.

Apesar das possíveis controvérsias, quer geradas pela própria imprecisão das categorias utilizadas como fáceis e difíceis ou das próprias variáveis escolhidas, Porter e Takeuschi indicam três fatores que devem ser considerados na análise de globalização de mercados:

1. características do consumidor: nível de renda, taxas de desemprego, educação e valores compartilhados pela sociedade;

17. JAIN, S. C. Op. cit.
2. infra-estrutura mercadológica: as mídias disponíveis, estruturas de distri- buição, transporte e comunicações, fatores ambientais e restrições legais;

3. diferenças competitivas: o grau de concorrência existente em cada mercado. Por exemplo: mercados com pouca ou nenhuma concorrência permitem uma maior padronização, enquanto mercados extremamente competitivos exigem adaptações de produto de maneira a atender mais eficientemente os segmentos visados.

Com base nesta análise é possível desenhar as seguintes opções estratégicas:

1. criar um produto com uma demanda universal, portanto, totalmente padronizado ou com modificações insignificantes. Exemplo: Coca-Cola;

2. atender um segmento universal: caso específico de produtos de luxo com apelos globais. Exemplo: MercedesBenz;

3. atender segmentos diferenciados com o mesmo produto: máquina fotográfica Canon AE-1 que no Japão buscava um mercado jovem; nos EUA, pessoas com renda e educação acima da média que estavam comprando pela primeira vez uma câmara fotográfica $35 \mathrm{~mm}$ e, na Alemanha, um mercado mais velho, sofisticado tecnologicamente, que estava substituindo seu equipamento fotográfico;

4. agrupar países em função de sua similaridade: através de hábitos culturais, religiosos, desenvolvimento econômi$\mathrm{co}$, infra-estrutura etc.

Nota-se que a preocupação de Porter e Takeuschi é analisar atentamente os fatores que limitam a globalização das estratégias de marketing e a partir delas fornecer opções para as empresas, no sentido de eliminação de custos e ganhos de economia de escala através da padronização de alguns elementos do composto de marketing.

Jain ${ }^{17}$ parece seguir a mesma linha de raciocínio de Porter e Takeuschi. Sua preocupação básica, no entanto, não é desenvolver um modelo prescritivo de 
ação, mas um arcabouço conceitual que permita detectar quais as condições que poderão permitir ou dificultar o desenvolvimento de padronização das estratégias de marketing. Os fatores são:

1. target market: inclui a área geográfica $\mathrm{e}$ fatores econômicos;

2. posicionamento de mercado: condições e desenvolvimento de mercado e nível de competição;

3. características do produto: tipo de produto e posicionamento;

4. meio ambiente: legal, econômico, infra-estrutura de marketing e ambiente físico.

Cada um destes fatores contribuem para a decisão de padronização da seguinte forma:

1. target market: a padronização é possível devido à tendência dos mercados se tornarem similares tendo como causa a comunicação e a tecnologia, além da mobilidade dos consumidores (especialmente europeus, norte-americanos e japoneses). Outros fatores apontados são as similaridades macroeconômicas como o PNB, renda discricionária, além de variáveis como nível educacional e penetração dos veículos de comunicação de massa. Estas avaliações permitem, a Jain, formular duas hipóteses: e a padronização é facilitada em países com semelhanças econômicas; a segmentação se torna mais útil com base nas características dos consumidores do que com base geográfica;

2. posicionamento de mercado: deve ser entendido como resultado de diferenças culturais, econômicas e de percepção do consumidor. $\mathrm{O}$ ato de compra $\mathrm{e}$ o valor atribuído ao produto são carregados de aspectos culturais e quanto maior a similaridade de significados entre os países, maior a possibilidade de padronização. Porém, mesmo em casos em que houver similaridades culturais e de percepção, as diferenças econômicas podem determinar a necessidade de adaptação do produto. Por exemplo, em países em desenvolvimento os automóveis devem sofrer reduções de custo a fim de atingir a classe média, sem no entanto reduzir a qualidade funcional. $O$ entendimento psicológico do produto por parte do consumidor é dado pela percepção, em caso de mercados em que os consumidores apresentem diferentes percepções do produto podem ser necessárias algumas adaptações. Outro fator determinante da adaptação ou não do produto é o nível de competição existente no mercado, mesma concepção de Porter - mercados altamente competitivos exigem adaptações dos produtos e vice-versa;

3. natureza do produto: produtos industriais e high-tech são mais suscetíveis à padronização devido ao fato de satisfazerem uma necessidade universal e por isso necessitarem de pequena ou nenhuma adaptação;

4. meio ambiente: a infra-estrutura mercadológica e as restrições legais, aduaneiras, impostos etc. afetam a estratégia mercadológica. A hipótese é de que quanto maiores as diferenças no ambiente físico, legal, político e infraestrutura mercadológica menor o grau de padronização possível.

\section{CONCLUSÕES}

Se observarmos atentamente os modelos propostos por Porter, Takeuschi e Jain, bem como os propostos por Wind, Keegan e outros verificaremos que na essência todos apresentam as mesmas idéias de formas diferentes. Muitas vezes, trata-se apenas de um exercício de nominação e tautologia. As questões colocadas seguem a mesma lógica de análise para a decisão de globalizar ou não, mas se utilizam dos mesmos conceitos para explicar a mesma coisa, conforme veremos a seguir: 


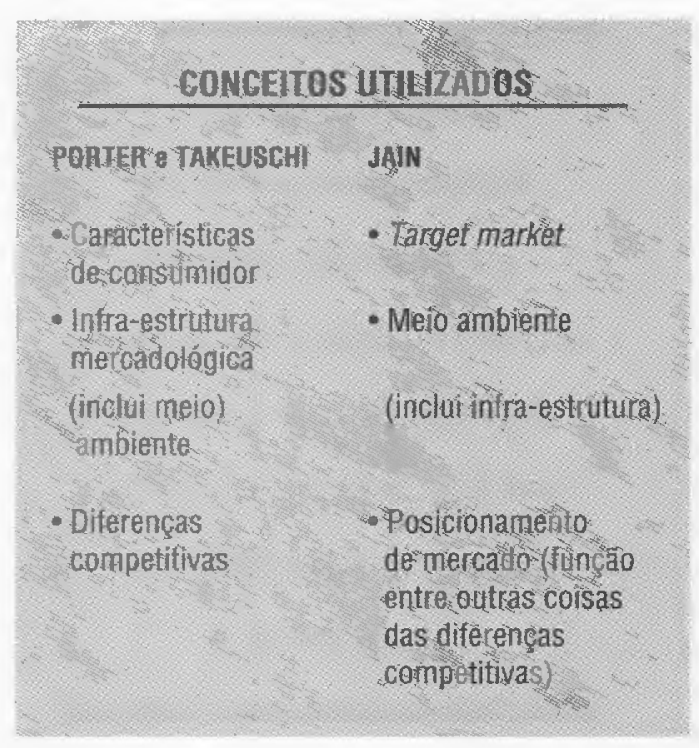

Apesar da aparente diferença nas análises destes autores a respeito das condiçōes a serem consideradas na decisão de padronização das variáveis do composto mercadológico, na verdade, eles estão propondo as mesmas coisas com diferentes nomes. Em outras palavras, no processo de globalização deve-se analisar as seguintes variáveis:

1. existência de um mesmo segmento de consumidores (evidentemente com as mesmas necessidades e características) para dado produto em um determinado número de países;

2. análise criteriosa da infra-estrutura mercadológica que permita a aplicação ou não da mesma estratégia de marketing;

3. a natureza da competição existente em cada país. Ou seja, estruturas competitivas diversas exigirão adaptação dos elementos que compõem a estratégia mercadológica.

Todos os demais autores como Wind, Keegan, Kotler e outros acabam sendo conduzidos por este mesmo modelo de análise, em que se busca determinar fatores que limitam ou permitam a padronizaçăo dos elementos que compõem o composto mercadológico. Entretanto, já tivemos oportunidade de mostrar no decorrer deste trabalho as diferenças encontradas em diversos países no que se refere à infra-estrutura mercadológica. Não devemos esquecer que mesmo entre países desenvolvidos esta infra-estrutura difere significativamente como na comparaçāo entre Japão e EUA no número de atacadistas utilizados; restrições no uso da televisão entre os diversos países; e diferenças na estrutura varejista, entre países como Bélgica, Itália, Japão, Portugal e Espanha, que ao contrário dos EUA e do Brasil, têm mais de $75 \%$ da venda de produtos alimentícios em pequenos estabelecimentos comerciais. O próprio leitor poderá se lembrar de inúmeras outras diferenças significativas entre os diversos países no que se refere à infra-estrutura mercadológica, como por exemplo: telecomunicações, logística, mídias disponiveis, sistemas de distribuição etc. E não devemos subestimar o efeito destas diferenças, uma vez que elas exigirão, de alguma forma, a adaptação do mix de marketing.

Quanto às características dos consumidores, não há evidências de que segmentos universais tenham se tornado regra e não exceção. Conforme já vimos, parece existir um segmento universal para determinados produtos de luxo, entretanto, até o momento, não existem estudos que apontem para uma tendência de proliferação destes segmentos. Ao contrário, a própria formação de blocos econômicos não aponta para uma homogeneização cultural, mas sugere uma tendência de valorização das culturas locais que poderão ter reflexos nos hábitos de consumo. Empresas tipificadas como globais acabam sempre por promover alguma alteração do produto, que, segundo Kotler, atinge cerca de $80 \%$ dos produtos.

Subre o nível de competição Sheth ${ }^{18}$ já havia chamado a atenção para a possível confusão entre concorrência global e mercado global. Para ele, a competição global tem ocorrido em todos os setores industriais, desde os mais tradicionais como químico e siderúrgico até bens de consumo, sem que isto implique uma universalidade dos desejos e necessidades dos consumidores. Como Kotler e Wind, ele participa do ponto de vista "pensar globalmente e agir localmente".

A idéia de que um baixo nível competitivo permite uma maior padronização é uma afirmação um tanto quanto óbvia, pois pressupōe uma situação monopolista em que a empresa pode se dar ao luxo de adotar uma orientação para o produto e não para o consumidor, e este é um dos motivos que obriga as empresas em mercados altamente competitivos a diferenciarem seus produtos de forma a atender mais eficientemente as necessidades e desejos dos consumidores.

Com base nestes fatos podemos con-
Markets or Global Competition. Journas of Consumer Marketing. v. 3, ก. 2, 1986. 
cluir que o conceito de Marketing Global, desenvolvido por Levitt, se mostrou inadequado e de pouca utilidade. As diferenças culturais, econômicas, sociais, legais, políticas e outras que se constituem no macro-ambiente de marketing e que determinam e condicionam as estratégias mercadológicas, têm sido apontadas por diversos autores como elementos que dificultam a aplicação do Marketing Global.

Por outro lado, o conceito de Levitt, apesar de ter se mostrado inoperante, continha em seu interior uma promessa extremamente atraente para as empresas: um enorme e ávido mercado, extremamente homogêneo (os únicos atributos desejados: qualidade e preço) e que a única regra do jogo seria a redução dos custos pela economia de escala. Portanto, Levitt propõe uma forte orientação para o produto e para a produção no mais puro regresso ao "qualquer um pode ter um Ford, desde que seja preto".

Esta promessa atraiu vários estudiosos e praticantes, que mesmo reconhecendo a impossibilidade de aplicação do conceito em seu estado puro, buscaram alternativas para a idéia de globalização. Contudo, as contribuições no sentido de operacionalizar o conceito de globalização e permitir a padronização dos elementos do mix de marketing são de um caráter evidentemente restritivo, o que acaba por tornar o próprio conceito vago e impreciso, limitando sua utilidade.

De certa forma, o que se pode depreender de tudo que foi comentado é que se tem buscado formas de segmentação de mercado a nível global ou até mesmo internacional. E, em alguns casos, as discussões se reduzem à procura de bases para a realização de uma segmentação eficaz a nível internacional.

Em uma leitura mais atenta, podemos verificar que os autores que buscam a padronização do composto de marketing, na verdade, discutem os critérios que permitem agrupar países ou regiões, que nada mais são do que a definição de variáveis para um processo de segmentação. No caso de Jain, as bases utilizadas são as características dos consumidores e as similaridades econômicas entre os diversos países. Porter e Takeuschi, por outro lado, reconhecem a existência de uma demanda universal para determinados pro- dutos, mas apontam para uma segmentação de países tendo como base a infra-estrutura mercadológica ou características dos consumidores. Logo, a aplicação do Marketing Global tem se transformado num exercício de segmentação cruzada, ou seja, utilizando-se de várias bases para a definição de um segmento. Este fato nos leva a acreditar que as empresas podem adotar uma estratégia global sem adotar o conceito de Marketing Global de Levitt e tão pouco total adaptação a cada mercado.

Isto se torna possível devido ao fato de que, apesar dos países apresentarem diferenças significativas, eles também possuem certas similaridades. Baseando-se neste aspecto, torna-se perfeitamente possível aplicar análises estatísticas para agrupar os países em função de sua similaridade utilizando para isso algumas variáveis consideradas críticas como: econômicas, sócio-culturais, tecnológicas, físicas, nível competitivo, governamentais e de estrutura de mercado ${ }^{19}$. Em última instância estas variáveis constituem o macro-ambiente de marketing e a similaridade deste é que irá permitir a adoção ou não da padronização do composto mercadológico. Assim, através de técnicas estatísticas, é possível agrupar países em diversos segmentos e desenhar estratégias para cada um deles. Em outras palavras, a adoção do processo de segmentação nos permite adotar a clássica estratégia de marketing diferenciado a nível de um ambiente de competição global onde se tem programas de marketing distintos para cada segmento.

Portanto, podemos concluir que o conceito desenvolvido inicialmente por Levitt não resistiu às evidências empíricas. Quanto às tentativas de seus seguidores, no sentido de validá-lo, fez com que os mesmos acabassem por discutir a forma mais eficiente de aplicar esta velha e conhecida técnica, dos praticantes e estudiosos de marketing, chamada Segmentação de Mercado.
19. Neste sentido, por exemplo, podemos utilizar a análise de Cluster que permite criar grupos onde os elementos integrantes de cada grupo são homogêneos entre si, mas distintos dos elementos dos demais grupos. 